\title{
Pedagogical Conditions for the Effective Formation of Creative Thinking of Art Students
}

\author{
Abizhanova Assem ${ }^{1}$, Nurazkhan Almaz ${ }^{2}$, Kabylov Daulet ${ }^{3}$, Mombek Aliya ${ }^{1}$, Kanapiyanova \\ Raushan $^{1}$, Tugelbayeva Gulmira ${ }^{4}$ and Aimbetova Ulbossyn ${ }^{5}$
}

\author{
${ }^{1}$ Abay Kazakh National Pedagogical University; ${ }^{2}$ Kazakh National Museum; ${ }^{3}$ International University Astana; \\ ${ }^{4}$ Military Institute of Land Forces; ${ }^{5}$ Academy of Choreography, Kazakhstan
}

\begin{abstract}
The essence of the concept "creative thinking" is considered, and its working definition is formulated. Special attention is given to the identification of pedagogical foundations of future teachers' creative thinking development, which accounting will promote the increase of the efficiency of the considered process. Future teachers' creative thinking development is advantageously realized in the course of students' vocational training, during which it is necessary to rely not only on mental development regularities knowledge (theoretical thinking, creative thinking peculiarities, sustained attention, imagination, and integration of memory) and students' individual characteristics (maturity of motivation to creative activities, the maturity of speech, volitional powers) but also on the competently organized didactic process (training to work with the concepts and their use, application of the system of creative tasks, developing the ability to overcome intellectual difficulties).

Results of students' activity studying on the basis of creative tasks have shown that creative thinking skills development depends on the students' thinking orientation in the processing of the received educational information; Also, creative thinking skills development depends on students' subjective attitude towards tasks, that is going to be helpful them during the educational process.

This study aims to examine the essence of the concept of "creative thinking" and identify pedagogical foundations for its development in future teachers.

The following methods of scientific and pedagogical research are used to achieve the objectives: the methods of theoretical research: the analysis of psychological and educational literature; methods of empirical research: students' activity products' studying, observation, conversation, pedagogical experiment.
\end{abstract}

Keywords: Pedagogical, conditions, effective formation, creative, thinking, students, Art.

\section{INTRODUCTION}

Nowadays, experts' creative work experience is demanded in many companies working in the field of technologies, production, and data analysis. The main trend in social labor development at the present stage is its intellectualization. It appears in an increase of specialists engaged in intellectual work and indicates the demand for experts' creative experience in many areas of modern life [1]. Consequently, there is a need to develop undergraduates' adaptive and flexible creative thinking at higher school. Such abilities as non-standard thinking, making unexpected conclusions can be useful in many areas in the future. The formation of highly skilled university graduates with a culture of thinking as the most important background of research thinking development is one of the strategic reference points of higher education modernization. Thereby, particular importance should be given to future teachers' creative thinking development. The formation of highly qualified professionals with advanced creative thinking is one of the conditions for the effective solution of such urgent problems as improving the education quality [2].

*Address correspondence to this author at the Kazakh State National University of Al-Farabi, Almaty, Kazakhstan; Tel: +77073851878;

E-mail: zhanat_2006@mail.ru
Various aspects of thinking investigated and disclosed in the works of B.G. Ananyev, L.S. Vygodsky, P.Ya. Galperin, V.V. Davydov, A.N. Leontyev, Ge. Piaget, S.L. Rubenstein, D.B. Elkonin, etc. [3]. They established that thinking is carried out in such intellectual operations as analysis and synthesis, identification and distinction, abstraction and generalization, etc. J. Dewey noted the importance of the research component in thinking [4]. He stated the first distinguishing feature of creative thinking is that it originates from facts and is a study, quick and covering a wide area of reality observation. He focused on helping a man in the world's creative development and research solution for vital tasks. A.F. Anufriyev writes that creative thinking is directed at solving theoretical and empirical problems that help obtain such data that cannot be used in practice in the near future but are valuable for science because they open prospects of its further learning [5]. Based on this, we can say that creative thinking is associated with facts' accumulation, which is a perspective for science at the present stage of society's development. According to N.V. Petrova and M.A. Belyalova, one of the components of research culture is creative thinking as the ability to generate new knowledge [6]. They emphasize that creative thinking is associated with self-inquiry, 
research skills, and personality research qualities, which are a part of the research culture. R. Kumar considers that creative thinking is a logical and rational way of thinking which induces the investigation of each arising problem. He notes that creative thinking contributes to the quality of professional work that makes you develop the ability to ask yourself such questions: What do I do? Why do I do this? How can I improve its performance? Creative thinking is studied in different spheres of professional activity [7]. Thus, T.V. Dontsova and A.D. Arnautova allocate creative thinking as a structural component of thinking. They claim that creative thinking is directed at determining the task's novelty, the ability to justify and reason actions, and received results. M.G. Gorbenko considers creative thinking as a necessary component in the art training process. She thinks that the nature of creative thinking reflects such types of thinking as analytical, creative, holistic, critical, heuristic, dialectic, irrational, emotionalfigurative, logical, and theoretical. In the definition of "creative thinking," she attaches special significance to the fact that its essential feature is active interaction with other thinking types [8].

Nowadays, the requirements of the teacher's activity and identity are significantly raised. They are increasingly becoming highly intelligent, necessitating the development of future teachers' theoretical and creative thinking. In this regard, that is not incidentally, K. Murdoch defines such a concept as "investigating teacher" who owns "skills of higher-order thinking" [9]. She focuses attention on that the teacher has to think crucially (or convergent), creatively (or divergent), reflexive (or meta-cognitive). The definitions of the concept "creative thinking" formulated by different scientists allowed to reveal the following signs are characterizing it: a problem existence and ability to formulate its essence; reflexive, critical, creative, logical, theoretical abilities of thinking; ability and readiness to define novelty and to find a contradiction (a problem); ability to accumulate information; ability to creative and productive, speech and to other kinds of activity; ability to make various assumptions (hypotheses), to build proofs; ability to research activity, etc. The analysis of interpretations of the concept "creative thinking" and identification of its signs allows to formulate its author's working definition: "creative thinking is an integrative process which combines features of various types of thinking and mental processes (imagination, fantasy), and is characterized as a culture of thinking focused on the solution of a certain problem or achievement of a specific goal, accumulating, synthesizing knowledge and formulating of new concepts in the process of the cognitive activity" [10]. It is impossible to receive desirable results without teachers' active inclusion as its direct participant in the general secondary education system's modernization process. To actively engage in the search for the general laws that identify causal relationships between the different educational facts and phenomena and influence them, it is necessary to develop creative thinking. In this regard, it is important to consider the pedagogical foundations of its development in students, future teachers. B.G. Ananyev considers that the life period from 17 to 25 years is important as the final stage of personality's formation and the main stage of professionalizing [11]. The high level of thinking development indicates the student's high potential, the ability of a person not only to perceive and capture information but also actively refine it for the solution of various problems, which is an especially important skill in research thinking development. According to N.S. Leites, students receive an inner need for abstract-logical thinking, so they can identify and pose problems, see the nonstandard approach to already known problems, and include private problems is more common. Divergent thinking begins dominating students, suggesting that the same question may have a set of equally valid and equivalent responses [12]. Besides, according to A.M. Gazaliyev, characteristics of student's age are such indicators as: steady attention, the developed imagination, big integration of memory. All these features of student's age can be considered not only as sensitive prerequisites for creative thinking development in future teachers but also as for pedagogical influence for their further development, in order to increase the intellectual potential of the student's individuality. While studying a particular student, it is necessary to consider the individual characteristics and peculiarities of students' mental processes and states [13]. At this age, people are trying to find their place in society, seeking to understand themselves. They are more critical, not only to themselves but also to others. According to the activity theory, thinking develops only in the course of the corresponding kind of activity implementation. From A.N. Leontyev's perspective, activity in its initial form is a sensual practical activity during which people engage in hands-on contact with world objects, and they are influenced by their resistance and affect them. Thus, creative thinking can only be developed if students are included in research activities [14]. A.N. Leontyev considers that mental activity, as well as practical 
activity, is carried out by means of practical operations, i.e., ways of action performance that in consequence is called theoretical activity, which is connected with theoretical thinking. Theoretical thinking has essentially unlimited potential of penetration into reality [15]. It is carried out in allocating and analyzing a basic contradiction of the studied situation or a solvable task. It is based on the analysis of the internal characteristics of the studied phenomena. It allows mentally changing the research object and to study it fully, opening internal characteristics and relations. These features reflecting the essence of theoretical thinking should be considered during the teaching and educational process organization to satisfy the needs of students for deep comprehension of the entity of the processes and the phenomena studied by them [16].

One more personal quality significant for successful future teachers' creative thinking development is the definiteness of their professional intentions and conscious participation in the considered process, which is expressed in students' motivation. Students who are motivated on creative thinking development have such characteristics as sensitivity and emotional reactivity, mobility of nervous processes, endurance to continuous and intensive work. The motivation influences the success of training and development of students' identity, defines their activity in the educational process, and successfulness in the future professional activity [17].

\section{METHODOLOGY}

\section{Participants}

The research was conducted based on KAZNPU, named after Abay among the second-course students of faculties of the Art (totally 90 students).

\section{Procedure}

The research involved the trial forming pedagogical experiment and provided students' performance of creative tasks on such educational art subject.

Creative tasks are the tasks given to students containing a problem that solution demands carrying out theoretical analysis, applying one or several scientific research methods, which means students open earlier unknown knowledge. The tasks performance was carried out on the following algorithm: task explanation by a teacher and its discussion together with students; literature review and its studying by students; work's theoretical part composition (performance form was arbitrary); work's final composition and its presentation; discussion, checking and estimation of results of performance.

\section{Instrument}

The following examples of research tasks were given to students:

1. Reveal teachers' and principals' administrative activity components. On this basis, develop the principal's model as an educational institution's manager and the teacher's model as a pupils' educational, cognitive activity manager.

2. Study the principles of state policy in the field of education and educational system management. Using the mass media resources and the Internet, find examples of the implementation and violations of these principles in the practice of secondary schools. Make a conversation plan for teachers aimed at revealing their views on the principles' implementation in the field of education and educational management of the school system.

3. Expand the features of interaction of such institutions as "school - family", "school - the State", "school - the mass media", "school public organizations", "school - school". Check out the experience of one of the secondary general education institutions of the city (district) and define how they implement interaction with various social institutions. Identify its goals, objectives, strengths, and weaknesses, and define the role of the teaching staff, school staff, students, and their parents, as well as public associations in the management of the institution.

4. Study a school development program and its allschool teaching and educational plan. Develop the model of the graduate on their basis. The existence of a problem which solution demands searching presents the distinguishing feature of tasks of research character. Implementation of these tasks contributes to the formation of the students' abilities to carry out multi-dimensional analysis of the problem based on integrating new and existing expertise and improving the skills of independent research. It is necessary to consider that successful performance of tasks of research character depends on the student's ability to focus on the process of tasks' implementation for a long time, to resort to 
strong-willed efforts in case of intellectual difficulties and the need to overcome them, the increased educational working ability, awareness of personal significance to solve such tasks for student's self-development, a larger amount of time spent on its implementation.

\section{RESULTS AND DATA ANALYSIS}

The criteria for assessing the quality of the research tasks' implementation are as follows: the depth of the analysis of literature; the volume of the basic and background knowledge attracted to tasks' solving, the student's ability to establish interdisciplinary and intrasubject relations; the degree of independence and creativity in tasks' solving; the originality of the findings and recommendations, their practice-oriented nature; the student's attitude to work, timely performance of tasks; the creativity of approaches to the solution of tasks, etc.

Results of the research showed that $38,9 \%$ of students successfully coped with tasks. Their works are distinguished by deep analysis, and answers were creatively different. While presenting their works, students were perfectly familiar with educational materials. Each of them felt confident and was ready to give answers to questions. The success of this group of students' implementation can also be explained by the fact that they repeatedly asked questions on assignments during the extracurricular time, which indicates students' serious attitude towards tasks and interest in their successful performance. These students desired to comprehend information newly and critically, commitment, determination, perseverance, independence, initiative, good memory, ability to concentrate, erudition, breadth of cognitive interests, and possession of Certain desired comprehension of knowledge. This group of students expressed special interest in tasks of the increased complexity level. $19 \%$ of students performed tasks with a few shortcomings. Their responses did not reflect depend on analysis, so that they had difficulties with the conclusion's formulation. These students performed tasks timely and were also familiar with the content. Students of this group showed independence, interest in research character tasks. However, it should be noted their assignments were performed not due to abilities to analyze but due to personal qualities such as a high level of formation of internal motivation, hard work, diligence, thoroughness, and accuracy in training activities. $14.5 \%$ of students were limited to facts' statements; their responses did not contain analytical data and were abstract in nature, which led students to false conclusions. Students belonging to this group are efficient, diligent, and capable of performing complicated tasks, but they do not desire a deeper and more thorough study; they are not interested in searching for original answers; they. They accept existing facts. They do not ask additional questions, which prompt the search. $11.6 \%$ of students came to school either not prepared or say they did not understand the assignment. Among them, some students systematically missed classes. This group of students is characterized by indifference to educational activities, lack of systematicity, working independently, and poor intrinsic motivation to active participation in the learning process.

\section{DISCUSSION}

Creative tasks are usually aimed at the convergence of education and science. Their educational value lies in the fact that they help the teacher to bring students to independent thinking and independent action; contribute to the formation of such qualities at students as thoughtfulness, patience, perseverance, endurance, accuracy, intelligence; develop a research approach to the studied technological processes [18]. The experience demonstrates that more successful task performance was done by the students with high academic progress and the students who are engaged in additional out-ofclass research activities. Successful performance of tasks was promoted by the accounting of the following individual and psychological features of students: orientation of students' thinking not only in the perception of information but also in its processing; students' subjective attitude to the tasks; the lack of fear to depart from the templates, the ability to offer bold ideas and solutions, to attract new sources and resources [19]. In the course of students' creative tasks performance, it was revealed that they experience several difficulties, such as: incorrectness of information collection or actual data, inability to work with concepts, to find and define a problem; to generalize or draw conclusions, to compare, isolate the basic idea, to analyze. Students do not identify the information found by them with what is required for the tasks' solution. They are experiencing difficulties related to their personal characteristics, such as: poor concentration, memory, will, perseverance, inability to think reflectively, critically, logically; the lack of interest and ability to research activity; domination of predisposition to reproductive educational activity, etc. In carrying out creative tasks, students needed help 
from the teacher of an advisory character. It consisted of a detailed explanation of a task, statement of the purpose together with the teacher, development of the algorithm, and the plan of work, determining sources and literature.

In some cases, students require a joint analysis of the answers. With the help of suggestive and provocative questions and reasoning, it was possible to find the correct answer [20]. Repeatedly it was necessary to motivate students to perform the task, explaining its relevance. Thus, students' creative tasks performance contributes to the development of their own ability to explain and justify the new facts, phenomena, and laws, as well as the formation of abilities to classify, compare, analyze and summarize previously studied phenomena and laws; establish causal connections and relationships; consider the same facts, phenomena, and laws from a new angle; apply the methods of scientific research (theoretical analysis and synthesis, modeling, etc.); find several solutions to the same problem, choose and justify the most rational answer; to review and evaluate their own work and the work of the comrades that promotes research thinking [21].

\section{CONCLUSION}

Creative thinking is the specific type of thinking culture formed in the course of purposeful cognitive activity. The teacher's creative thinking increases his independence in the continuously and spontaneously arising professional problems solving. It helps the teacher see a problem systemically, solve nonstandard character problems, and have a high level of complexity. To improve the creative thinking development process's efficiency, it is necessary to know the features of the student's age and consider them during future teachers' vocational training [22]. The research showed that when students' creative thinking development it is important to account pedagogical foundations, among which are: features of such mental informative processes as perception, memory, imagination, thinking, connected with specifics of student's age; motivation and the need for self-development, students' personal features connected with the students' leading kind of activity learning; age features of students' thinking; the level of student's proficiency: the organization of training process specific to student's age, including students' creative activity, focused on activation of their informative processes. Future teachers' creative thinking development is advantageously realized in the course of students' vocational training regardless of their level of training (bachelor's or master's degree), as the student's age is the most favorable for its development.

\section{REFERENCES}

[1] Kumar R. Research methodology: A step-by-step guide for beginners (4th ed.). California, Thousand Oaks: SAGE publication 2014; 98.

[2] Dontsova TV, Arnautova AD. Formation of engineering thinking in the course of design activity. Engineering Education 2014; 16: 70-75. Retrieved from http://aeer.ru/files/io/m16/art_8.pdf.

[3] Ananiev NG. Some problems of vocational guidance among schoolchildren: textbook. Ed. N.G. Ananiev. Rostov-on-Don: Phoenix, 2006; p. 38.

[4] Kavale J. Needs Assessment in Career Guidance and Counselling: Lack of Scientific Exploration and Justification? Indian Journal of Career and Livelihood Planning Journal of the Indian Association for Career and Livelihood Planning (IACLP) 2012; 1(1): 104-109.

[5] Dogar R, Azeem A, Majoka D, Mehmood și Latif. Need Assessment of Students' Guidance and Counseling. British Journal of Arts and Social Sciences 2011; 1(2): 324-329.

[6] Radulet A. Orientarea in cariera a studentilor, Ed. Accent Cluj-Napoca Savickas, M. L." The Theory and Practice of Career Construction" 2013; pp 76-87.

[7] Kozhakhmetova A, Ospanova Z, Mussatayeva M, Bissenbayeva $\mathrm{Zh}$. Axiological concepts of journalistic texts (Lingua-stylistic analysis) XLinguae 2020; 13(2): 225-234. https://doi.org/10.18355/XL.2020.13.02.19

[8] Guez W, Allen J. Guidance. 2000; Available from: http://www.unesco.org/education/mebam/module_1.pdf

[9] Tanveer-Uz-Zaman, Choudhary, But. Guidance and Counseling for Science Students: a Need Assessment. Indian Journal of Education and Information Management 2014; 3(4): 13-18.

[10] Freidus H, Baker C, Feldman S, Hirsch J, Stern L, Sayres B, Wiles-Kettenmann. Insights into self-guided professional development: Teachers and teacher educators working together. Studying Teachers Education 2009; 5(2): 183-194. https://doi.org/10.1080/17425960903306948

[11] Loo SY. Professional development of teachers: Using multimodality and reflective peer review approaches to analyze digitally recorded teaching practices. Teacher Development 2013; 17(4): 499-517. https://doi.org/10.1080/13664530.2013.838602

[12] Manning C, Morrison BR, Mcllroy T. MOOCs in language education and professional teacher development: Possibilities and potential. SiSAL Journal 2014; 5(3): 294308.

https://doi.org/10.37237/050308

[13] Minott MA. Reflective teaching as self-directed professional development: Building practical or work-related knowledge. Professional Development in Education 2010; 36(1-2): 325338.

https://doi.org/10.1080/19415250903457547

[14] Schlichte J, Yssel N, Merbler J. Pathways to burnout: Case studies in teacher isolation and alienation. Preventing Schoo Failure: Alternative Education for Children and Youth 2005; 50(1): 35-40. https://doi.org/10.3200/PSFL.50.1.35-40

[15] Utami ILP, Prestridge S. How English teachers learn in Indonesia: Tension between policy-driven and self-driven professional development. Teflin Journal 2018; 29(2): 245265.

https://doi.org/10.15639/teflinjournal.v29i2/245-265 
[16] Belkin PG, Yemelyanov EN, Ivanov MA. Social psychology of research team. - M: Science 1987; 11(2): 208-212.

[17] Ryan R, Deci E, Grolnick W. Autonomy, relatedness, and the self: Their relation to development and psycho-pathology. Developmental psychopathology. Eds. D. Cicchetti, D. Cohen. N.Y.: Wiley, 1995; 1: pp. 618-655.

[18] Hekhauzen $\mathrm{H}$. Motivation and activity. SPb.: St. Petersburg; M: Sciense, 2003; pp. 457-463.

[19] Maslow A. Motivation and personality. N.Y. 1954; pp. 532541.

[20] Amabile TM. Motivating Creativity in Organizations: On Doing What You Love and Loving What You Do. California Management Review 1997; 40(1): 39-58. https://doi.org/10.2307/41165921
[21]

Buelens V. Century, Herman M. An Analysis of Differences in Work Motivation between Public and Private Sector Organizations. Public Administration Review 2007; 8(4): 6574.

https://doi.org/10.1111/j.1540-6210.2006.00697.x

[22] Elliot Andrew J. Achievement Motivation. Encyclopedia of Social Psychology. 2007. SAGE Publications 2010; pp. 983994 http://www.sageereference.com/socialpsychology/Articl en3.html

Received on 14-11-2020

Accepted on 06-12-2020

Published on 09-12-2020

DOI: https://doi.org/10.6000/2292-2598.2020.08.04.24

(C) 2020 Assem et al.; Licensee Lifescience Global.

This is an open access article licensed under the terms of the Creative Commons Attribution Non-Commercial License (http://creativecommons.org/licenses/by-nc/3.0/) which permits unrestricted, non-commercial use, distribution and reproduction in any medium, provided the work is properly cited. 